\title{
Fractalkine as a severity marker of atopic dermatitis in infants and toddlers
}

\author{
Viktoriia Klymenko', Oleksandr Ashcheulov', Olena Vysotska², Anna Pecherska² \\ 'Department of Fundamentals of Pediatrics No. 2, Kharkiv National Medical University, Kharkiv, Ukraine \\ ${ }^{2}$ Department of Biomedical Engineering, Kharkiv National University of Radio Electronics, Kharkiv, Ukraine
}

\section{ABSTRACT}

Introduction: Atopic dermatitis $(\mathrm{AD})$ is a common chronic inflammatory skin disease.

The aim of the study were the relationship determining between level of serum fractalkine and clinical signs of $\mathrm{AD}$; and establishing correlation between the level of serum fractalkine and paraclinical signs of $\mathrm{AD}$ (total Ig E level, immunogram value).

Material and methods: 60 children with clinical manifestations of $\mathrm{AD}$ in the exacerbation period of the disease (main group) and 16 healthy children without chronic diseases (control group) took part in the clinical study. Results: The study showed that the serum fractalkine level is elevated in all forms of AD severity: mild - 8.55 (6.11-10.79) ng/ml, moderate - 10.97 (5.61-14.01) ng/ml, severe - 12.53 (9.01-16.68) ng/ml. It was also established that serum fractalkine levels correlate with the overall assessment of the AD severity on the SCORAD scale, total intensity of all lesions, erythema, excoriations, itching and sleep disturbances $(p<0.05)$. Direct correlation of fractalkine level count with neutrophil count $(27$ [24-71] $p<0.05)$, and vice versa - with the number of lymphocytes $(61.5[26-70] p<0.05)$ was uncovered when analyzing serum fractalkine levels and paraclinical criteria. The study found a connection between the serum fractalkine levels and immune indicators as well: inter alia the probable reduction of CD3, CD16, Ig G and the probable increase of CD4, CD22, CD25 and Ig E. Conclusion: Fractalkine can be used as an objective severity marker for acute phase of AD.

\section{KEY WORDS:}

children, atopic dermatitis, fractalkine.

\section{INTRODUCTION}

Atopic dermatitis (AD) is a common chronic inflammatory skin disease, its prevalence rate among children is approximately $10-20 \%[1,2]$.

Atopic dermatitis was first described in the seventeenth century. By the twentieth century sufficient clinical observations were accumulated and the main clinical signs of $\mathrm{AD}$ in the form the widely used today Hanifin-Rajka [3] diagnostic criteria were identified [4]. Further development of immunology allowed investigation of the abnormalities at the cellular level and formulation of the immunological concept of AD: it was proven that in acute lesions first-type helpers predominate, while in case of process chronisation the profile of second-type helpers prevails [5]. The twenty-first century marks a new stage in the study of $\mathrm{AD}$ problem at the molecular level: today not only molecules and receptors that mediate cellular interaction are known, but also new therapeutic strategies based on the relation of monoclonal antibodies to target mediators are being created. Thus, in the severe form AD the use of dupilumab - monoclonal antibodies to interle-

\section{ADDRESS FOR CORRESPONDENCE:}

Oleksandr Ashcheulov, MD, Department of Fundamentals of Pediatrics No. 2, Kharkiv National Medical

University, 4 Nauky Avenue, 61022 Kharkiv, Ukraine, tel.: +38 05040665 46, e-mail: oleksandr.ashcheulov@mail.ru 
ukin-4 (IL-4) and IL-13 is possible [6], while in mild and moderate forms of $\mathrm{AD}$ the effectiveness of crisaborole the inhibitor of phosphodiesterase- 4 - has been proven [7]. Thus, the main direction of scientific research in the study of $\mathrm{AD}$ at present is the study of individual molecules, receptors, mediators of allergic inflammation.

Among chemokines and chemokine receptors associated with allergic inflammation, elevated levels of CX3CL1 (fractalkine) and its unique receptor (CX3CR1) were detected during $\mathrm{AD}[8]$.

Chemokines are peptides that regulate cellular interaction. In the skin chemokines are secreted both by resident cells, such as keratinocytes, melanocytes, fibroblasts, dendritic, mast cells, and other cells that penetrate the skin - lymphocytes, eosinophils, and monocytes. Chemokines are involved in the induction and maintenance of the inflammatory process in the skin and regulate the emergence of cell infiltrates. The accumulation of activated mast cells in the affected areas of the skin forms the skin manifestations of $\mathrm{AD}$.

Fractalkine exists in two forms: cell-bound membrane and soluble. In its membrane-bound form fractalkine acts as a molecule of adhesion, whereas in its soluble form it acts as chemoattractant for T-cells, NK-cells, and monocytes. Recent studies have shown that fractalkine is expressed on cells of the monocyte-macrophage series, which in turn contributes to the circulation of dendritic cells through the inflamed lymphatic vessels [9].

The importance of fractalkine was noted in many inflammatory diseases, including rheumatoid arthritis, vasculitis, systemic sclerosis, and others [10, 11].

Therefore, fractalkine can be considered as a potential biomarker for assessing the severity of the disease in patients with allergic diseases. Therapeutic interventions for $\mathrm{AD}$ in children aimed at fractalkine deserve further scientific research.

\section{AIM OF THE STUDY}

The aim of the study is to determine the relationship between level of serum fractalkine and clinical signs of $\mathrm{AD}$; to establish the correlation between the level of serum fractalkine and paraclinical signs of AD (total IgE level, immunogram value).

\section{MATERIAL AND METHODS}

The research was carried out on the basis of the Department of Children of Younger Age the Regional Children's Allergological Centre and the Consultation Clinic of Kharkiv Regional Clinical Children Hospital No. 1. The study involved 60 children with clinical manifestations of $\mathrm{AD}$ in the exacerbation period of the disease (main group) and 16 healthy children without chronic diseases (control group).

The patients selected for examination were children aged from 29 days to 3 years with clinical manifestations of AD. Patients with complications of AD (bacterial or fungal skin infections, lymphadenitis, etc.), congenital defects, other chronic diseases, any acute illness or lack of compliance with parents were excluded from participation in the study.

In addition to traditional clinical-paraclinical examination, the study included an assessment of AD severity based on the scoring of atopic dermatitis index (SCORAD), the determination of immunological parameters (CD3 CD4, CD8, CD16, CD22, CD25, IgA, IgM, $\operatorname{IgG})$ and total $\operatorname{IgE}$ level.

The determination of fractalkine levels was performed by enzyme-linked immunosorbent assay using human fractalkine ELISA reagents manufactured by RayBiotech Inc., USA.

This study was performed according to the ethical principles of the Declaration of Helsinki and the ethical norms and orders of the Ministry of Health of Ukraine. After explaining the aim and methods of the study, written informed consent was taken from parents of all participants.

The statistical software StatSoft STATISTICA version 7.0 for Windows was used for statistical analysis. The Mann-Whitney $U$ test was used for abnormally distributed continuous variables, and data were presented as medians and interquartile ranges. A $p$-level of less than 0.05 was considered significant.

\section{RESULTS}

Sixty children were examined: $63 \%$ boys and $37 \%$ girls. The division of groups is shown in Table 1.

TABLE 1. The division of children in groups based on age, sex, and severity of AD

\begin{tabular}{|c|c|c|c|c|c|c|c|c|}
\hline \multirow{2}{*}{$\frac{\text { Age }}{\text { Sex }}$} & \multicolumn{2}{|c|}{ From 1 month to 1 year } & \multicolumn{2}{|c|}{ From 1 year to 2 years } & \multicolumn{2}{|c|}{ From 2 years to 3 years } & \multicolumn{2}{|l|}{ Total } \\
\hline & Boys & Girls & Boys & Girls & Boys & Girls & Boys & Girls \\
\hline \multicolumn{9}{|l|}{ Severity } \\
\hline Mild & 4 & 3 & 4 & 2 & 2 & 1 & 10 & 6 \\
\hline Moderate & 3 & 5 & 3 & 2 & 3 & 5 & 9 & 12 \\
\hline Severe & 3 & 1 & 13 & 1 & 3 & 2 & 19 & 4 \\
\hline \multirow[t]{2}{*}{ Total } & 10 & 9 & 20 & 5 & 8 & 8 & 38 & 22 \\
\hline & \multicolumn{2}{|c|}{19} & \multicolumn{2}{|c|}{25} & \multicolumn{2}{|c|}{16} & & \\
\hline
\end{tabular}


TABLE 2. The level of serum fractalkine in patients depending on the presence of asphyxia

\begin{tabular}{|l|c|c|}
\hline & $\begin{array}{c}\text { Assessment of the } \\
\text { child's condition } \\
\text { in the first minute, } \\
\% \text { of children }\end{array}$ & $\begin{array}{c}\text { The level } \\
\text { of fractalkine, } \\
\mathrm{ng} / \mathrm{ml}\end{array}$ \\
\hline $\begin{array}{l}\text { Normal index } \\
\text { on the Apgar scale }\end{array}$ & 81 & $11.66(8.27-14.38)^{*}$ \\
\hline $\begin{array}{l}\text { Children } \\
\text { with asphyxia }\end{array}$ & 19 & $6.84(5.59-11.11)^{*}$ \\
${ }^{*} p<0.05$ & &
\end{tabular}

All children were suffering from $\mathrm{AD}$ and were divided according to $\mathrm{AD}$ severity (depending on the SCORAD index): mild $-27 \%$, moderate $-35 \%$, and severe cases $-38 \%$.

Regarding the features of the AD course it should be noted that in $38 \%$ of the children's lesions were of limited character, while $62 \%$ had widespread manifestations. However, the severity of morphological lesions (the total score of all morphological elements on the SCORAD scale) was insignificantly mild - only in $17 \%$ of children was the intensity index more than 10 points. The subjective component was the most difficult one to evaluate because infants and toddlers usually do not experience itching, so it is hard to determine the cause of sleep disturbances and the connection of the above with $\mathrm{AD}$ exacerbation. However, $23 \%$ of patients suffered from itching rated up to 5 points and $77 \%$ of the patients rated more than 5 points. Sleep disturbances occurred in $63 \%$ of the cases.

From the anamnesis of the disease, it is known that the first clinical manifestations of $\mathrm{AD}$ are detected on average starting from the age of 4 months, namely $51 \%$ - until 3 months, $33 \%$ - from 3 to 6 months, 16\% - from 6 months to 1 year. The course of the disease is characterised by frequent exacerbations, in particular: $41 \%$ - more than 6 times per year, 30\% - 4-6 exacerbations, and 29\% - less than 2. During treatment the majority of patients used moisturising agents (86\%), topical glucocorticoids (43\%), and antihistamines (74\%).

It is known from the patients' life history that half of the mothers (51\%) had normal pregnancy, $18 \%$ had over-vomiting during the pregnancy period, $12 \%$ had the threat of preterm delivery, $11 \%$ had placental insufficien$\mathrm{cy}$, and $8 \%$ of the pregnant women had anaemia. Only $20 \%$ of the mothers followed a hypoallergenic diet during pregnancy.
Most of the deliveries (97\%) were on time, 2\% were pre-term, and $1 \%$ were post-term. In $73 \%$ of cases the delivery was physiological, and in $27 \%$ it was by C-section. Nineteen per cent of the children were born in asphyxia. The level of serum fractalkine was significantly lower among children born in asphyxia (Table 2).

As a result of the study, a link was established between the severity of $\mathrm{AD}$ clinical manifestations and the serum fractalkine level (Table 3).

Given the existence of a reliable difference in the fractalkine levels in the mild and severe progression of $\mathrm{AD}$, the correlation links with the main indicators characterizing the clinical course of AD were calculated (Table 4). Even though all indicators were directly linked, the most reliable and significant ones were indicators that primarily reflect the acuteness of the process.

Positive correlation of fractalkine level count with neutrophil count $(27[24-71] p<0.05)$, and vice versa with the number of lymphocytes $(61.5[26-70] p<0.05)$ was uncovered when analysing serum fractalkine levels and paraclinical criteria. Probable reductions of CD3, CD16, and IgG increases in CD4, CD22, CD25, and IgE were found when studying the immunological status. The levels of CD8, IgA and IgM ratios were within normal limits for their respective age. Indicators of cellular and humoral immunity are shown in Figs. 1 and 2.

Reliable positive correlations $(p<0.05)$ were established between the level of serum fractalkine and CD8, stimulated neutrophil activation index and lysosomal-cationic proteins. Pending the examination of correlations between the total IgE level and the serum fractalkine level, a change in the direction of the correlation was found, ranging from a positive link in the mild form of $\mathrm{AD}$ to a negative link in the medium and severe forms. A change in the direction of correlation links in the said context is considered as a depletion of adaptation mechanisms.

\section{DISCUSSION}

In modern literature fractalkine is considered as a multifactorial marker. It is studied not only with $\mathrm{AD}$, but also with asthma, allergic rhinitis, and other autoimmune diseases. It is confirmed by the scarcity of works of fractalkine binding with $\mathrm{AD}$ in general, and in particular in young children.

Many works have described in the experiment on the model (mouse) that the value of fractalkine is shown,

TABLE 3. The level of serum fractalkine in children, depending on the severity of $A D$

\begin{tabular}{|l|c|c|c|c|}
\hline & \multicolumn{3}{|c|}{ The severity of AD } & $\begin{array}{c}\text { Control group } \\
(n=16)\end{array}$ \\
\cline { 2 - 5 } & $\begin{array}{c}\text { Mild } \\
(n=16)\end{array}$ & $\begin{array}{c}\text { Moderate } \\
(n=21)\end{array}$ & $\begin{array}{c}\text { Severe } \\
(n=23)\end{array}$ & $\begin{array}{c}\text { 12.53 } \\
\text { Fractalkine, }\end{array}$ \\
$\mathrm{ng} / \mathrm{ml}$
\end{tabular}

${ }^{*} p<0.01$ compared to severe $A D, " p<0.01$ compared to the norm, ${ }^{,} p<0.001$ compared to the norm 
TABLE 4. Correlation between SCORAD and fractalkine levels

\begin{tabular}{|l|c|c|}
\hline Indicator & $\begin{array}{c}\text { Coefficient } \\
\text { of correlation }\end{array}$ & $p$-value \\
\hline SCORAD - total & 0.271 & 0.007 \\
\hline $\begin{array}{l}\text { The prevalence } \\
\text { of dermatitis }\end{array}$ & 0.188 & 0.08 \\
\hline Total intensity of all lesions & 0.235 & 0.011 \\
\hline Erythema & 0.258 & 0.016 \\
\hline Excoriation & 0.209 & 0.037 \\
\hline Papule/oedema & 0.107 & 0.298 \\
\hline Oozing/crusting & 0.112 & 0.269 \\
\hline Lichenification & 0.153 & 0.129 \\
\hline Itching & 0.249 & 0.009 \\
\hline Sleep disturbances & 0.272 & 0.005 \\
\hline
\end{tabular}

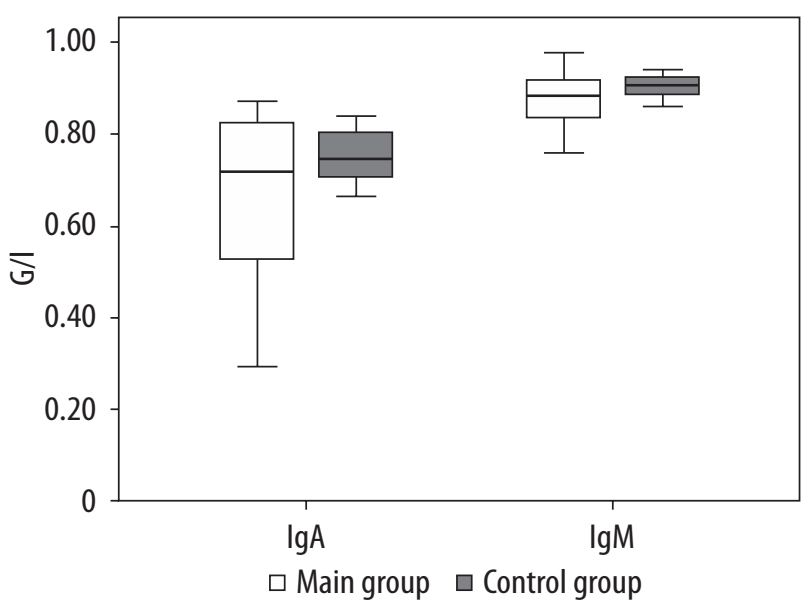

FIGURE 2. Characteristics of humoral immunity indicators in children with $A D$

but the characteristics of the reception vary in humans and mice. In humans, CX3CR1 has two known ligands: CX3CL1 and CCL26 (eotaxin-3). In mice, the CCL26 gene is however a pseudogene, and CX3CL1 is therefore the only known ligand of CX3CR1 [12].

It is important to clarify the meaning of fractalkine in humans. The serum fractalkine is elevated only in some people with $\mathrm{AD}$. In $\mathrm{AD}$ patients, CX3CL1 is up-regulated in both endothelial cells and skin lesions, and serum CX3CL1 levels are positively associated with disease severity [13]. Another study reported that, although CX3CR1 mRNA expression is consistently up-regulated in $\mathrm{AD}$ skin, CX3CL1 mRNA levels are only increased in some patients with a significant correlation to the disease severity [14].

The study of this topic is important not only for a scientific purposes, but also for the search for a new targeted treatment of AD. Although inhaled corticosteroids are very effective as an anti-inflammatory treatment for persistent asthma, they do not cure asthma. Furthermore, $10 \%$ of asthmatic patients do not respond to this treatment [15]. More specific therapeutic agents such as

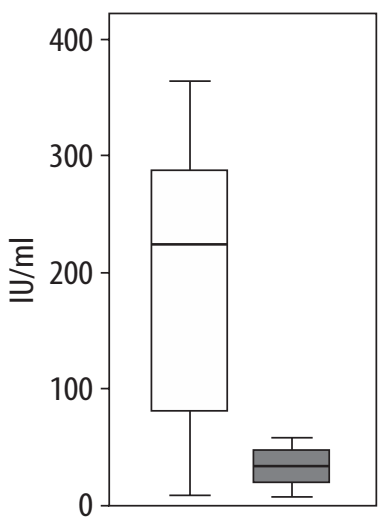

0

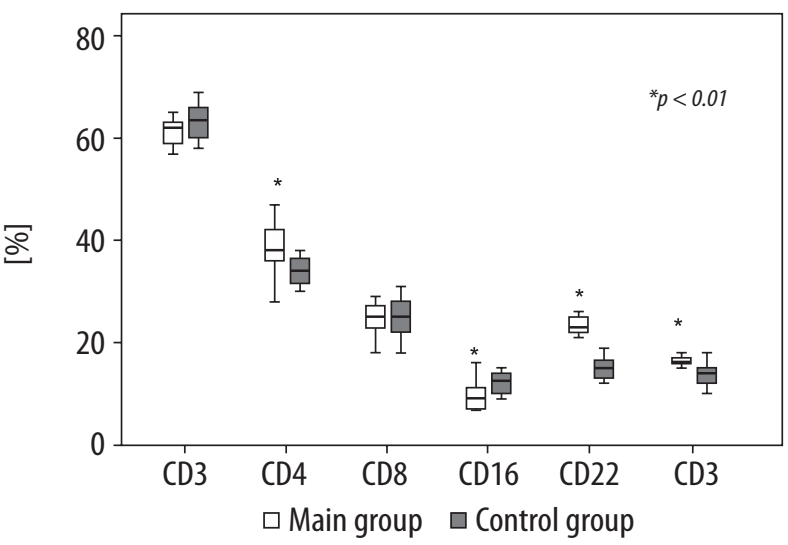

FIGURE 1. Characteristics of cellular immunity indicators in children with $A D$

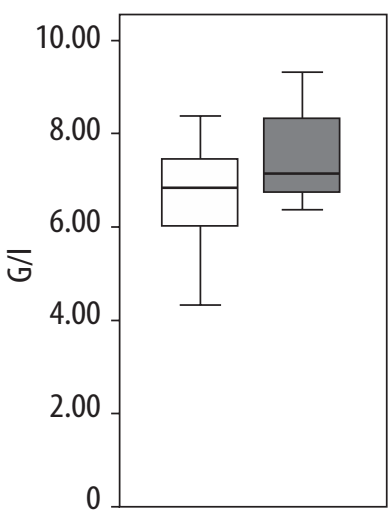

antibodies to IL- 5 have been tested in clinical trials, but the results have been rather disappointing [16]. The same studies are needed for the role of fractalkine in AD.

\section{CONCLUSIONS}

The level of serum fractalkine is elevated in all forms of $\mathrm{AD}$ severity and correlates with the overall assessment of the severity of AD on the SCORAD scale, the total intensity of all lesions, erythema, excoriations, itching and sleep disturbances. There are established correlation bonds to the level of fractalkine: positive - with the number of neutrophils, CD8 lymphocytes, stimulated neutrophil activation index, and lysosomal-cationic proteins; negative - with the number of lymphocytes. The level of serum fractalkine can be used as an objective severity marker for acute phase of $\mathrm{AD}$.

\section{DISCLOSURE}

The authors declare no conflict of interest. 


\section{REFERENCES}

1. Odhiambo JA, Williams HC, Clayton TO, et al. ISAAC Phase Three Study Group. Global variations in prevalence of eczema symptoms in children from ISAAC Phase Three. J Allergy Clin Immunol 2009; 124: 1251-1258.e23.

2. Tay YK, Kong KH, Khoo L, et al. The prevalence and descriptive epidemiology of atopic dermatitis in Singapore school children. $\mathrm{Br}$ J Dermatol 2002; 146: 101-106.

3. Hanifin JM. Diagnostic features of atopic dermatitis. Acta Derm Venereol (Suppl.) 1980; 92: 44-47.

4. Andersen RM, Thyssen JP, Maibach HI. Qualitative vs. quantitative atopic dermatitis criteria - in historical and present perspectives. J Eur Acad Dermatol Venereol 2016; 30: 604-618.

5. Grewe M, Bruijnzeel-Koomen CA, Schöpf E, et al. A role for Th1 and Th2 cells in the immunopathogenesis of atopic dermatitis. Immunol Today 1998; 19: 359-361.

6. Beck LA, Thaçi D, Hamilton JD, et al. Dupilumab treatment in adults with moderate-to-severe atopic dermatitis. N Engl J Med 2014; 371: 130-139.

7. Zane LT, Chanda S, Jarnagin K, et al. Crisaborole and its potential role in treating atopic dermatitis: overview of early clinical studies. Immunotherapy 2016; 8: 853-866.

8. Staumont-Sallé D, Fleury S, Lazzari A, et al. CX3CL1 (fractalkine) and its receptor CX3CR1 regulate atopic dermatitis by controlling effector T cell retention in inflamed skin. J Exp Med 2014; 211: 1185-1196.

9. Nedoszytko B, Sokołowska-Wojdyło M, Ruckemann-Dziurdzińska $\mathrm{K}$, et al. Chemokines and cytokines network in the pathogenesis of the inflammatory skin diseases: atopic dermatitis, psoriasis and skin mastocytosis. Postepy Dermatol Alergol 2014; 31: 84-91.

10. Kim JE, Kim JS, Cho DH, et al. Molecular mechanisms of cutaneous inflammatory disorder: atopic dermatitis. Int J Mol Sci 2016; 17: pii: E1234.

11. Sugaya M. Chemokines and skin diseases. Arch Immunol Ther Exp (Warsz) 2015; 63: 109-115.

12. Echigo T, Hasegawa M, Shimada Y, et al. Expression of fractalkine and its receptor, CX 3 CR1, in atopic dermatitis: possible contribution to skin inflammation. J Allergy Clin Immunol 2004; 113 : 940-948.

13. Tremblay K, Lemire M, Provost V, et al. Association study between the CX3CR1 gene and asthma. Genes Immun 2006; 7: 632-639.

14. Nakayama T, Watanabe $\mathrm{Y}$, Oiso N, et al. Eotaxin-3/CC chemokine ligand 26 is a functional ligand for CX3CR1. J Immunolo 2010; 185: 6472-6479.

15. Lopez Vina A. Severe asthma refractory to treatment: concepts and realities. Arch Bronconeumol 2006; 42: 20-25.

16. O'Byrne PM. The demise of anti IL-5 for asthma, or not. Am J Respir Crit Care Med 2007; 176: 1059-1060. 